\section{P1-432 VIOLENCE AND HEALTH: AN EPIDEMIOLOGICAL ANALYSIS OF HOMICIDES IN MÉXICO, 1979-2008}

doi:10.1136/jech.2011.142976g.22

G J Gonzalez-Perez, ${ }^{*}$ M G Vega-lopez, C E Cabrera-pivaral, A Vega-lopez. University of Guadalajara, Guadalajara, Mexico

Introduction This study seeks to analyse the trend of homicide rate in México in last 30 years by age, gender and mechanism of death and identify the socioeconomic variables that better explain the spatial variations of homicide rate in Mexico in 2000 and 2008.

Methods Homicide rates adjusted by age were calculated; through the use of multiple regression analysis (stepwise method), variables that better explained the interstate variations in the homicide rates were identified.

Results The results show that although homicide rates in Mexico have been relatively high, the rate markedly decreased between early nineties and 2005, but has increased around 35\% in last 3 years; furthermore, years of potential life lost by homicide has increased in recent years because the victims are younger; currently, male homicide rate is nine times higher than female rate; throughout the period more than half of homicides were committed by firearms, and in recent years figures exceed $60 \%$. Moreover, social exclusion, drug trafficking, impunity and firearms possession are key elements to understand the spatial variations of the homicide mortality in Mexico in analysed years.

Conclusions In recent years it is observed a rise of the homicide rate and consequently, an increment of the social insecurity at a national level; to reduce the number of homicide victims and spatial variations in the rate, the Mexican government needs to combat the cartels of drug trafficking, but also to implement structural reforms to improve the life conditions of Mexican population and diminish the socioeconomic disparities among states.

\section{P1-433 CAESAREAN SECTION IN PRIMIPAROUS, ADOLESCENTS MOTHERS OF GUADALAJARA, MEXICO: LEVEL AND ASSOCIATED FACTORS}

doi:10.1136/jech.2011.142976g.23

G J Gonzalez-Perez, ${ }^{*}$ M G Vega-lopez, C E Cabrera-pivaral. University of Guadalajara, Guadalajara, Mexico

Introduction Mexico has in recent years one of the highest rates of caesarean sections in the world and in turn, high rates of adolescent fertility. This study seeks to know the caesarean rate and to identify factors socioeconomic and related to medical practice associated to caesarean section in primiparous mothers under 20 years old in Metropolitan Area of Guadalajara, Mexico.

Methods The study was conducted at various public hospitals randomly selected of different health institutions of the MAG. A cross-sectional study was carried out, collecting data of all $<20$ years old primiparous mothers that had their delivery at the hospitals included in study during the second half of 2008 (sample size: caesarean section 306, vaginal delivery 462). A logistic regression model was used to estimate ORs with $95 \%$ CIs.

Results Almost $40 \%$ of total deliveries were by caesarean section. In the multivariate analysis five factors were statistically associated with the caesarean section: labour induction (OR $=5.2$, CI 2.8 to 9.5), body mass index $\geq 26$ (OR $=4.0$, CI 1.7 to 9.4 ), low socioeconomic level $(\mathrm{OR}=2.9$, CI 1.5 to 5.7$)$, birth weight $>3.500 \mathrm{~g}(\mathrm{OR}=2.0$, CI 1.0 to 4.2$)$ and maternal age $18-19(\mathrm{OR}=3.4$, CI 1.6 to 7.1$)$.

Conclusions The cesarean section rate among adolescents is extremely high. Identified factors suggest the necessity of an adequate prenatal care to control those aspects that could lead to a caesarean section, but also the importance of quality care during childbirth to try to reduce the observed rates in the MAG.
P1-434 BIRTH OUTCOMES AND EARLY-LIFE SOCIAL CHARACTERISTICS PREDICT UNEQUAL EDUCATIONAL OUTCOMES ACROSS THE LIFECOURSE AND ACROSS GENERATIONS. DATA FROM A SWEDISH COHORT BORN 1915-1929 AND THEIR GRANDCHILDREN BORN 1973-1980

doi:10.1136/jech.2011.142976g.24

${ }^{1,2} \mathrm{~A}$ Goodman, ${ }^{2} \mathrm{M}$ Gisselmann, ${ }^{2} \mathrm{~K}$ Koupil. 'London School of Hygiene and Tropical Medicine, London, UK; ${ }^{2}$ Centre for Health Equity Studies, Stockholm University, Karolinska Institute, Stockholm, Sweden

Educational inequalities are a major contributor to health and social inequalities. We investigated the effects of adverse birth characteristics and social disadvantage upon educational outcomes over the lifecourse and across generations. Our subjects were 12674 Swedish infants born 1915-1929 and 9706 of their grandchildren born 1973-1980. Within both cohorts, better school achievement (schoolmarks in elementary school) was predicted by: heavier birthweight, lower birth order, older mother, married mother and higher family social class. These effects persisted after mutualadjustment, and birth characteristics and family composition played little role in explaining social class effects. There were no independent effects of preterm or twin status, but weak evidence that postterm infants were disadvantaged. The predictors of education continuation (secondary school attendance and entrance to tertiary education) were very similar, with family composition and social class effects persisting even after adjusting for school achievement. Across generations, better grandchild educational outcomes were predicted by heavier birthweight, lower birth order and higher social class in the grandparents. These associations became non-significant and/or substantially attenuated after adjusting for grandchild socioeconomic position in childhood, suggesting this was the major mechanism for this effect. We conclude that multiple early-life characteristics predict educational outcomes across the lifecourse and across generations, including birth outcome and family composition effects which typically receive little attention. Most effects were remarkably stable, suggesting their relevance for understanding educational inequalities in other populations. Such understanding would, in turn, clarify a major mechanism whereby health inequalities emerge across the lifecourse and are recreated across generations.

\section{P1-435 WHY DO BRITISH INDIAN CHILDREN HAVE AN APPARENT MENTAL HEALTH ADVANTAGE}

doi:10.1136/jech.2011.142976g.25

A Goodman,* V Patel, D Leon. London School of Hygiene and Tropical Medicine, London, UK

Background Previous studies document a mental health advantage in British Indian children, the causes of which are unknown.

Methods Our subjects were 13836 White children and 361 Indian children aged 5-16 years in the British Child and Adolescent Mental Health Surveys. Mental health was assessed using the parent, teacher and child Strengths and Difficulties Questionnaires (SDQs), and multi-informant clinician-rated diagnoses. Multiple child, family, school and area factors were examined as possible mediators or confounders of ethnic differences.

Results Indian children had a large advantage for externalising problems/disorders, and no difference for internalising problems/ disorders. This was observed across all outcomes, and psychometric analyses provided no suggestion of information bias. The Indian advantage for externalising problems was partly mediated by Indian children being more likely to live in two-parent families and less likely to have academic difficulties. Yet after adjusting for these and 